\title{
Instruction Manual: River Function Questionnaire
}

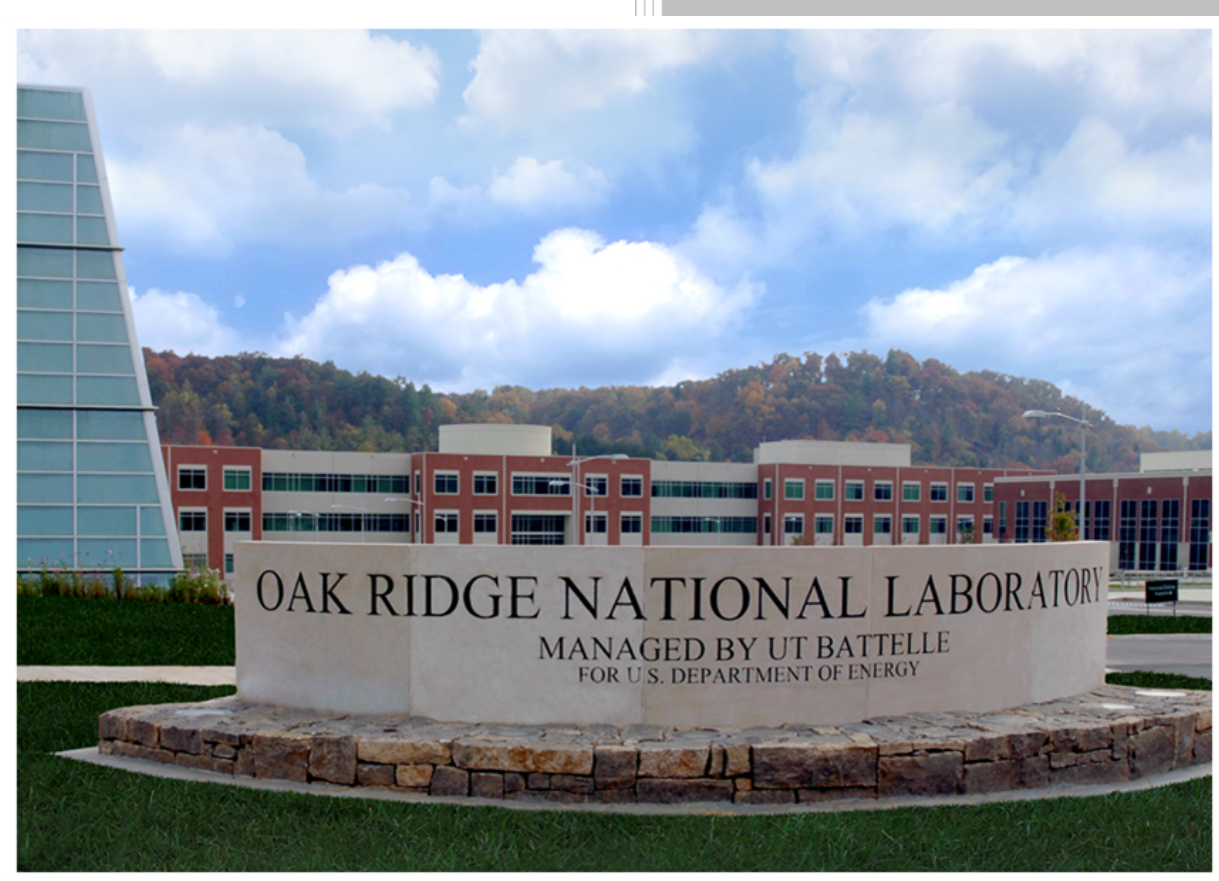

Ryan A. McManamay

Brenda M. Pracheil

Shelaine L. Curd

Brennan T. Smith

Esther Parish

Adam Witt

Anna West

Kelsey Rugani

Christopher R. DeRolph

Mary Beth Day

May 2019 


\section{DOCUMENT AVAILABILITY}

Reports produced after January 1, 1996, are generally available free via US Department of Energy (DOE) SciTech Connect.

Website www.osti.gov

Reports produced before January 1, 1996, may be purchased by members of the public from the following source:

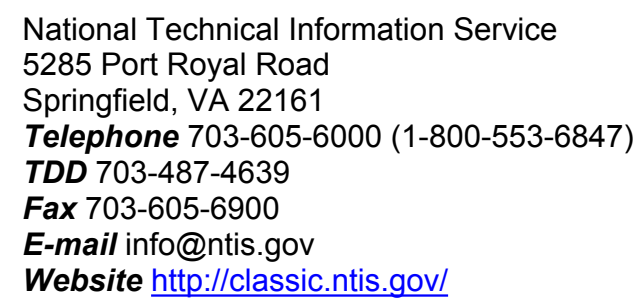

Reports are available to DOE employees, DOE contractors, Energy Technology Data Exchange representatives, and International Nuclear Information System representatives from the following source:

Office of Scientific and Technical Information

PO Box 62

Oak Ridge, TN 37831

Telephone 865-576-8401

Fax 865-576-5728

E-mail reports@osti.gov

Website http://www.osti.gov/contact.html

This report was prepared as an account of work sponsored by an agency of the United States Government. Neither the United States Government nor any agency thereof, nor any of their employees, makes any warranty, express or implied, or assumes any legal liability or responsibility for the accuracy, completeness, or usefulness of any information, apparatus, product, or process disclosed, or represents that its use would not infringe privately owned rights. Reference herein to any specific commercial product, process, or service by trade name, trademark, manufacturer, or otherwise, does not necessarily constitute or imply its endorsement, recommendation, or favoring by the United States Government or any agency thereof. The views and opinions of authors expressed herein do not necessarily state or reflect those of the United States Government or any agency thereof. 
Environmental Science Division

INSTRUCTION MANUAL: RIVER FUNCTION QUESTIONNAIRE

\author{
Ryan A. McManamay \\ Brenda M. Pracheil \\ Shelaine L. Curd \\ Brennan T. Smith \\ Esther Parish \\ Adam Witt \\ Anna West \\ Kelsey Rugani \\ Christopher R. DeRolph \\ Mary Beth Day
}

May 2019

Prepared by

OAK RIDGE NATIONAL LABORATORY

Oak Ridge, TN 37831-6283

managed by

UT-BATTELLE, LLC

for the

US DEPARTMENT OF ENERGY

under contract DE-AC05-00OR22725 



\section{CONTENTS}

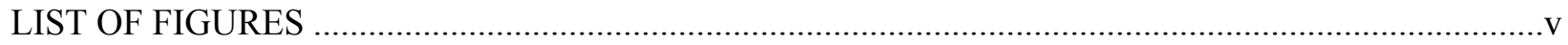

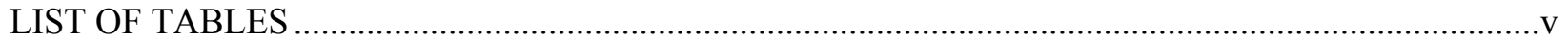

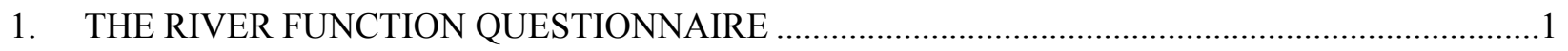

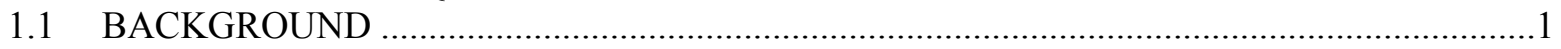

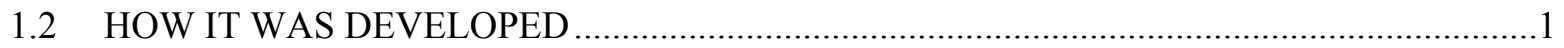

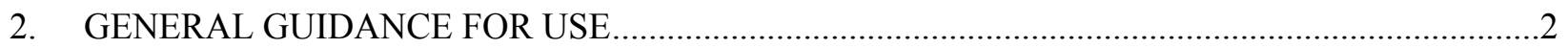

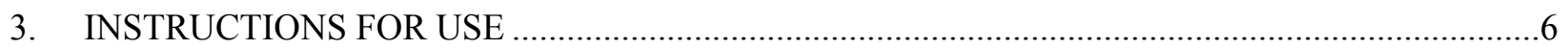

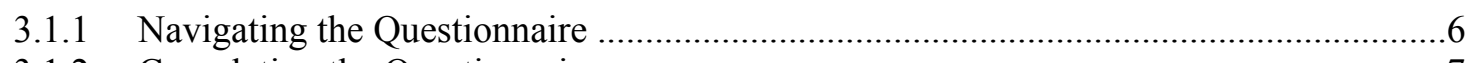

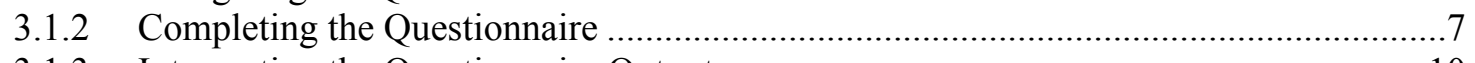

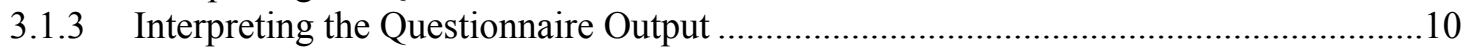

4. QUESTIONNAIRE CROSS-CUT WITH REGULATORY CRITERIA …...................................17

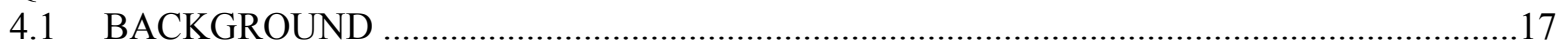

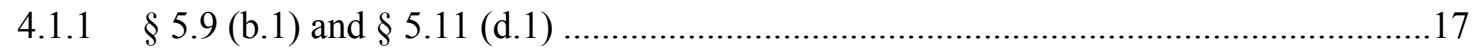

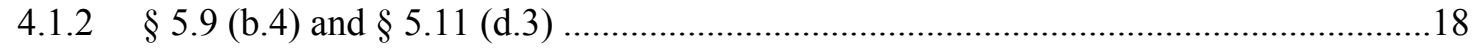

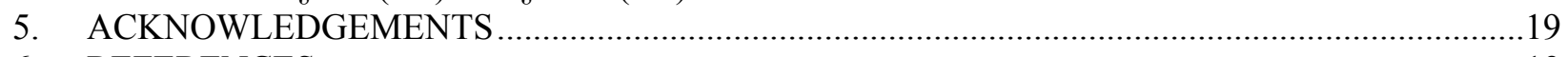

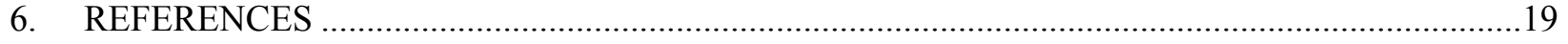





\section{LIST OF FIGURES}

Figure 2.1. Instruction spreadsheet providing an overview of background, purpose, and general insructions for use.

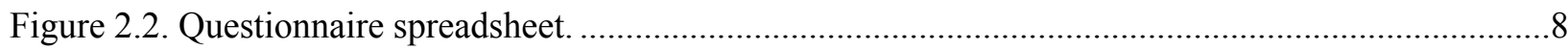

Figure 2.3. (A) Inset displays the response to questions provided by a drop-down list. ...........................8

Figure 2.4. Section of questionnaire for determining whether specific taxa (columns) apply to each question.

Figure 2.5. At the bottom of the questionnaire, there is a navigation button (red circle) that takes

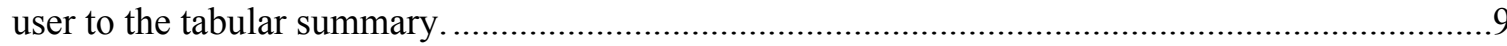

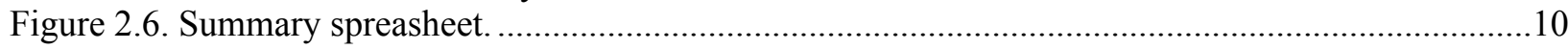

Figure 2.7. Top of Bar_plot spreadsheet with navigation buttons and first two bar plots.........................10

Figure 2.8. Bar plot depicting the percentage of "yes", "no", and "uncertain" responses relevant to

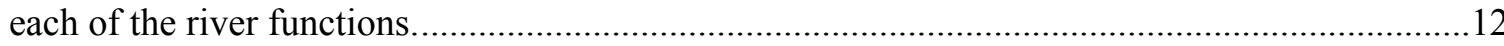

Figure 2.9. Bar plot depicting the percentage of "yes" responses that were relevant to specific

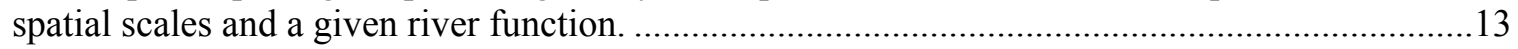

Figure 2.10. Bar plot depicting the percentage of "yes" responses that were relevant to specific

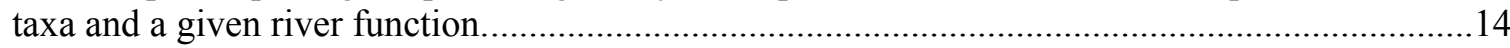

Figure 2.11. Spider diagram depicting the proportion of questions answered "Yes" for each river function.

Figure 2.12. Spider diagram spreadsheet provides navigational buttons (to navigate to other sheets) and provides convenient print buttons to print the diagram or the river function summary table to .pdf.

\section{LIST OF TABLES}

Table 2.1. River functions and their descriptions used as indicators of the effects of hydropower on the river environment. From Pracheil et al. (in review). 



\section{THE RIVER FUNCTION QUESTIONNAIRE}

\subsection{BACKGROUND}

The regulatory process for US hydropower is time- and resource-intensive to all involved. For instance, licensing new facilities or relicensing existing facilities, including pre-negotiation procedures, may take in excess of 15 years. This process typically involves evaluating project effects through a scoping and study implementation process. While some studies are critical to understanding project effects, certain studies may be unnecessary if they do not directly connect with potential project effects.

Part of the attempt of determining environmental issues is defining what constitutes "the environment" effected by hydropower development and operations. In a recent literature review and meta-analysis on global hydropower-environmental studies, Parish et al. (2019) assembled a meta-analysis and database representing the "universe" of potential environmental metrics used to measure the effects of hydropower on river environments (completed Fiscal Year (FY) 2018). Subsequently, Pracheil et al. (in review) categorized these metrics into 51 non-reducible river functions, which represent the dimensions of the hydropower-river environment. These functions provide a template to reduce complexity by organizing environmental effects into a series of indicator groups.

The River Function Questionnaire (Questionnaire) is a series of questions designed to help stakeholders determine the impacts of hydropower on river functions as outlined in Pracheil et al. (in review; Table 2.1) that may need to be understood or addressed through additional field studies or environmental assessments. In order to provide a platform accessible to many users, we developed the questionnaire in Microsoft Excel with convenient macro-enabled interactive features, such as print and navigation buttons. The Questionnaire was developed under the Department of Energy (DOE)-funded Environmental Metrics for Hydropower (EMH) project in FY 2018. The Questionnaire was iteratively reviewed by a 25-member advisory Board comprised of federal and state agencies, environmental non-governmental organizations, utility and developer interests, tribes, and scientists. After each review, the Questionnaire was subsequently updated to incorporate Board member comments.

The Questionnaire was designed with the expectation that individuals familiar with the specific river system and facility, preferably natural resource experts, would complete the questions. Ideally, Questionnaire users should also have some familiarity with major concepts in river ecology (e.g., River Continuum Concept, Vannote et al. 1980; Natural Flow Regime, Poff et al. 1997; Indicators of Hydrologic Alteration, Richter et al. 1996) and the environmental effects of hydropower. Individuals filling out the Questionnaire will likely be environmental consultants as an early-stage assessment, or resource agencies and NGOs familiar with the system or having years of experience working with the system.

\subsection{HOW IT WAS DEVELOPED}

ORNL assembled an initial compilation of 425 journal articles and reports from previous projects and reviews related to environmental effects of hydropower, including: environmental indicators for hydropower sustainability (Parish et al. 2019), future hydropower planning, siting, and landscape considerations (McManamay et al. 2015b); environmental flows, habitat fragmentation, and geomorphic considerations (McManamay 2014; McManamay et al. 2010, 2012, 2013a, 2015a; 2016a), meta-analyses of hydrologic alterations from dams (Poff and Zimmerman 2010; McManamay et al. 2013b), types of dams and hydropower operations (Poff and Hart 2002; McManamay et al. 2016b), and effects of dams on water quality (Olden et al. 2010). We then selected literature pertaining to each river function individually with the objective of identifying generalized effects of dams on each function and what factors could serve as predictors or indicators of those effects. 
Each of the questions are considered "generic" to identify common environmental effects of hydropower and dams on river functions and are accompanied by a scientific reference to scientifically justify inclusion of the question. Questions were determined through scientific literature review and the direction of effect is based on outcomes of consensus among multiple sources (See "Bibliography" in Questionnaire). While it is recognized that dams and specific rivers are complex and inherently contextspecific, there is much scientific literature that suggests that some environmental responses are generic to dams, given certain properties of the structure and the river. For example, a diversion-bypass that dewaters a stream is likely to result in riparian encroachment on the stream channel. As another example, a dam that discharges water from the hypolimnion of a thermally stratified reservoir is likely to result in lower temperatures than would normally be expected. In these cases, the phenomena above lead to more evidence for evaluating the "Stream Channel" and "Water Temperature" river functions, respectively.

Each question pertains to at least one river function but may pertain to multiple river functions. On average, there are five questions supporting each river function, but the number of questions per function may range from four to eight. All questions must be answered "yes", "no", "uncertain", or "not applicable". Based on all answers, the total "yes", "no", and "uncertain" responses for a given river function are totaled and provided in a final summary table and graphs.

Questions were framed using an eco-evidence approach (Norris et al. 2012) and should be answered using existing information. All questions are structured in such a way that "yes" answers lead towards more evidence for a given river function being potentially impacted by a project or that might require further consideration. Questions answered "uncertain" also provide evidence of river functions where more information or data is needed. The questions (and associated river functions) are also organized by spatial scale (Basin, Project, Reservoir, and Downstream) and according to which types of taxa (e.g., fish, amphibian, bird, etc.) may be relevant. The spatial scale is automatically built into the Questionnaire, but users can specify which taxa are relevant to a given question by answering "yes" under each taxa column. These results are also summarized in the summary table.

An internal database keeps track of all responses, spatial scale relevance, taxa-relevance, and the river functions applicable to all responses. The Questionnaire automatically summarizes the number of questions answered "yes", "no", or "uncertain" responses according to river function. These summaries are provided in tabular and graphical form for users to evaluate evidence (from 0 to 1 ) for any river function.

\section{GENERAL GUIDANCE FOR USE}

The River Function Questionnaire is one component of the Environmental Decision Support (EDS) Toolkit and was created to help foster dialog among stakeholders and to focus discussions about the study needs of a given hydropower project. However, the Toolkit does not recommend or suggest mitigation actions or study methodology. For example, the Questionnaire may foster discussions regarding what environmental conditions are uncertain or where existing information is available or needed to address a given environmental issue (i.e., river function). The Questionnaire can be used at any stage of the FERC licensing procedure, but its most suitable application was envisioned for early in the regulatory process as project details and potential impacts are starting to be assessed.

Thus, used of the Toolkit may include (but not limited to):

1) hydropower applicants in identifying potential environmental issues within the Pre-Application Document (PAD) or Stage 1 Consultation 
2) environmental stakeholders in identifying knowledge gaps and environmental concerns needing to be addressed through studies or mitigation, and/or

3) all stakeholders within scoping phases discussing what environmental issues need to be addressed.

All questions must be answered "yes", "no", "uncertain", or "not applicable". Furthermore, to affirmatively answer a question as "yes" or "no", some form of existing information must be provided (e.g., data, analysis, picture, literature, website, stream gage reading, etc). Questions were written so that "yes" answers provide more evidence of an affected river function, questions answered "uncertain" also provide an indication of where more information or data is needed. If questions cannot be answered "yes" or "no" confidently and with evidence, questions should be answered as "uncertain" or "not applicable". In some cases, questions may not be relevant to the project such as in cases where a resource does not exist at a facility or when an impact to a river function may be caused by an already existing alteration. For instance, environmental assessments evaluating the addition of hydropower to existing non-powered dams typically only consider the environmental effects of adding electrical generation infrastructure (e.g., turbines, penstocks, powerhouse) and not the pre-existing effects of the dam and reservoir. In these cases, answers to questions targeting dam development, in general, might be answered "not applicable".

Table 2.1. River functions and their descriptions used as indicators of the effects of hydropower on the river environment. From Pracheil et al. (in review).

\begin{tabular}{|l|l|l|l|}
\hline Function Level & Code & \multicolumn{1}{|c|}{ River Function Name } & \multicolumn{1}{c|}{ River Function Description } \\
\hline $\begin{array}{l}\text { Biota and } \\
\text { Biodiversity }\end{array}$ & F1 & Abundance, density & Count or other measures of organisms per area \\
\cline { 2 - 4 } & F51 & $\begin{array}{l}\text { Algae/ primary } \\
\text { productivity (BB) }\end{array}$ & $\begin{array}{l}\text { Algal blooms which lead to oxygen depletion and } \\
\text { eutrophication }\end{array}$ \\
\cline { 2 - 4 } & F5 & $\begin{array}{l}\text { Behavior, movement, } \\
\text { colonization, extinction }\end{array}$ & $\begin{array}{l}\text { Behavior of organisms in study area, including } \\
\text { colonization, movement patterns, distance, duration, } \\
\text { timing, frequency and/or extinction. }\end{array}$ \\
\cline { 2 - 4 } & F6 & $\begin{array}{l}\text { Demographics, age, sex, } \\
\text { size }\end{array}$ & Population demographics, including age, sex, and size \\
\cline { 2 - 4 } & F7 & $\begin{array}{l}\text { Fitness, survival, growth, } \\
\text { condition, reproduction, } \\
\text { mortality }\end{array}$ & $\begin{array}{l}\text { Fitness, survival, growth, condition, reproduction, or } \\
\text { mortality of organisms }\end{array}$ \\
\cline { 2 - 4 } & F8 & $\begin{array}{l}\text { Functional group, or } \\
\text { species or trait composition }\end{array}$ & $\begin{array}{l}\text { Grouping of organisms by functional or trait status, } \\
\text { percentage composition }\end{array}$ \\
\hline
\end{tabular}


Table 2.1. River functions and their descriptions used as indicators of the effects of hydropower on the river environment. From Pracheil et al. (in review). (continued)

\begin{tabular}{|c|c|c|c|}
\hline Function Level & Code & River Function Name & River Function Description \\
\hline & F9 & $\begin{array}{l}\text { Genetics, mixing, } \\
\text { metapopulation }\end{array}$ & $\begin{array}{l}\text { Genetics and population mixing, including } \\
\text { metapopulation dynamics }\end{array}$ \\
\hline & F10 & $\begin{array}{l}\text { Habitat, critical habitat, or } \\
\text { surrogates of such }\end{array}$ & $\begin{array}{l}\text { Indices of habitat, area, suitability, and so on, for } \\
\text { organisms }\end{array}$ \\
\hline & F11 & $\begin{array}{l}\text { Internal composition } \\
\text { nutrient abnormalities }\end{array}$ & $\begin{array}{l}\text { Nutritional composition and makeup of organisms, } \\
\text { including elemental stoichiometry. Includes levels of } \\
\text { internal homeostasis, as well as morphological, genetic, or } \\
\text { hormonal abnormalities caused by contaminants }\end{array}$ \\
\hline & F2 & $\begin{array}{l}\text { Life history trait } \\
\text { characteristics }\end{array}$ & $\begin{array}{l}\text { Life history trait characteristics and their values, such as } \\
\text { duration of spawning, fecundity, reproductive mode (note } \\
\text { this category deals only with characteristics themselves } \\
\text { and not the composition of the community.) }\end{array}$ \\
\hline & F3 & $\begin{array}{l}\text { Presence, absence, } \\
\text { occupancy, or detection }\end{array}$ & $\begin{array}{l}\text { Organism presence/absence in an area (including pseudo- } \\
\text { absence), occupancy, and detection probability }\end{array}$ \\
\hline & F4 & Species diversity & $\begin{array}{l}\text { Species richness, diversity, evenness, or indices-of-biotic- } \\
\text { integrity metrics used to characterize one or more } \\
\text { components of the biotic community }\end{array}$ \\
\hline \multirow[t]{11}{*}{ Water Quality } & F40 & $\begin{array}{l}\text { Algae/ primary } \\
\text { productivity (WQ) }\end{array}$ & $\begin{array}{l}\text { Algal concentration including measures of primary } \\
\text { productivity such as chlorophyll A or cyanotoxin. }\end{array}$ \\
\hline & F41 & Buffering capacity & Characteristics including $\mathrm{pH}$, alkalinity \\
\hline & F42 & Dissolved gasses & Concentration of non-greenhouse gases in water \\
\hline & F43 & Dissolved oxygen & Dissolved oxygen in water \\
\hline & F44 & Ecosystem function & $\begin{array}{l}\text { Ecosystem vital rates and processes, including gross } \\
\text { primary productivity, respiration, biochemical oxygen } \\
\text { demand }\end{array}$ \\
\hline & F45 & Gas emissions & $\begin{array}{l}\text { Concentration and ebullution of water-origin greenhouse } \\
\text { gases }\end{array}$ \\
\hline & F46 & Key elements & $\begin{array}{l}\text { Elements and compounds that are not listed on the EPA } \\
\text { Toxic and Priority Pollutants list }\end{array}$ \\
\hline & F47 & Macromolecular pollutants & $\begin{array}{l}\text { Pollutants listed on the EPA Toxic and Priority Pollutants } \\
\text { list that are not included in other EMH categories }\end{array}$ \\
\hline & F48 & $\begin{array}{l}\text { Nutrients and organic } \\
\text { material }(\mathrm{C}, \mathrm{N}, \mathrm{P})\end{array}$ & $\begin{array}{l}\text { Dissolved organic carbon and other organic non-pollutants } \\
\text { essential to life, including nitrogen, phosphorous, and } \\
\text { inorganic carbon. }\end{array}$ \\
\hline & F49 & $\begin{array}{l}\text { Solid transport, turbidity, } \\
\text { and conductivity }\end{array}$ & $\begin{array}{l}\text { Descriptions of dissolved and suspended solids in water } \\
\text { such as turbidity, suspended or dissolved solids, } \\
\text { conductance }\end{array}$ \\
\hline & F50 & Water temperature & Water temperature \\
\hline \multirow[t]{3}{*}{ Geomorphology } & F15 & $\begin{array}{l}\text { Catchment and basin } \\
\text { attributes }\end{array}$ & $\begin{array}{l}\text { Upland soil characteristics, topography, and landscape } \\
\text { erodibility metrics that could influence soil erosion and } \\
\text { wasting related and subsequent sedimentation related to } \\
\text { hydropower development }\end{array}$ \\
\hline & F16 & Channel & $\begin{array}{l}\text { Channel properties such as bankfull width, wetted width, } \\
\text { bankfull discharge, channel slope, braided channel, } \\
\text { channelization }\end{array}$ \\
\hline & F17 & Floodplain valley & $\begin{array}{l}\text { Metrics related to channel confinement, entrenchment, } \\
\text { migration, etc. }\end{array}$ \\
\hline
\end{tabular}


Table 2.1. River functions and their descriptions used as indicators of the effects of hydropower on the river environment. From Pracheil et al. (in review). (continued)

\begin{tabular}{|c|c|c|c|}
\hline Function Level & Code & River Function Name & River Function Description \\
\hline & F18 & Sediment and substrate & $\begin{array}{l}\text { Sediment and substrate properties such as substrate } \\
\text { particle size, bedload, sediment entrainment or deposition, } \\
\text { bedrock composition }\end{array}$ \\
\hline \multirow{3}{*}{$\begin{array}{l}\text { Connectivity and } \\
\text { Fragmentation }\end{array}$} & F12 & Basin area & Some aspect of area of river basin \\
\hline & F13 & $\begin{array}{l}\text { Dendritic network and } \\
\text { riverscape }\end{array}$ & $\begin{array}{l}\text { Fragment length, dendritic connectivity index, barrier } \\
\text { index, river distance between dams and projects }\end{array}$ \\
\hline & F14 & Fish passage & $\begin{array}{l}\text { Mitigated fish passage, including presence of upstream or } \\
\text { downstream passage or length of bypass }\end{array}$ \\
\hline \multirow[t]{6}{*}{ Water Quantity } & F24 & Basin attributes & $\begin{array}{l}\text { Attributes related to factors that influence hydrology (or } \\
\text { were used in the context of hydrology), such as climate } \\
\text { and precipitation }\end{array}$ \\
\hline & F25 & Diversion & $\begin{array}{l}\text { Quantitative properties of diversions such as volume or } \\
\text { discharge of diversion or water for other uses }\end{array}$ \\
\hline & $\begin{array}{l}\text { F26- } \\
\text { F31 }\end{array}$ & Downstream discharge & $\begin{array}{l}\text { Downstream discharge magnitude, duration, rate of } \\
\text { change, and timing associated with a specific flow } \\
\text { condition (Poff et al. 1997). }\end{array}$ \\
\hline & F32 & Groundwater & Groundwater characteristics \\
\hline & F33 & Reservoir hydrology & $\begin{array}{l}\text { Reservoir hydrological characteristics such as residence } \\
\text { time, reservoir fluctuation, reservoir surface area, or } \\
\text { degree of regulation }\end{array}$ \\
\hline & $\begin{array}{l}\text { F34- } \\
\text { F39 }\end{array}$ & Upstream inflows & $\begin{array}{l}\text { Upstream inflow magnitude, duration, rate of change, and } \\
\text { timing associated with a specific flow condition (Poff et } \\
\text { al. 1997). }\end{array}$ \\
\hline \multirow[t]{5}{*}{ Landscape } & F19 & Area impacted, project area & $\begin{array}{l}\text { Project boundary area, area impacted by the project as } \\
\text { whole, not related to reservoir inundation or land cover }\end{array}$ \\
\hline & F20 & $\begin{array}{l}\text { Floodplain or riparian } \\
\text { vegetation }\end{array}$ & $\begin{array}{l}\text { Properties of floodplain or riparian vegetation such as } \\
\text { riparian encroachment or floodplain area }\end{array}$ \\
\hline & F21 & Land cover class & Type of land cover, changes in land cover \\
\hline & F22 & Protected land & $\begin{array}{l}\text { Spatial properties of protected lands including losses or } \\
\text { increases }\end{array}$ \\
\hline & F23 & Reservoir inundation & $\begin{array}{l}\text { Reservoir area, upland or floodplain inundation, biomass } \\
\text { inundated/lost }\end{array}$ \\
\hline
\end{tabular}




\section{INSTRUCTIONS FOR USE}

\subsubsection{Navigating the Questionnaire}

The Questionnaire is a Microsoft Excel file that includes 10 spreadsheets. The spreadsheets include macro-enable features, such as navigation buttons and print commands. Below is a list of each spreadsheet and its function.

- Instructions - General overview of the questionnaire and a brief version of the details provided in the instructions

- Questionnaire - List of structured questions organized into major themes and pull-down lists of alternative responses to each answer and whether the question is relevant to specific taxa

- Summary - Table summarizing the responses to questions associated with each of the river functions. This tabular summary includes the responses according to different spatial scales and taxa.

- Bar Plots - These three figures summarize the results of the tabular information from the "Summary" Spreadsheet

- Spider Diagram - this diagram provides a different way to visualize information from the "Summary" spreadsheet. The spider diagram graphically depicts the evidence that a river function is affected by hydropower development or operations. Specifically, the diagram represents the proportion of questions answered "yes" pertaining to each of the river functions.

- Question_Details: List of questions and their attributes including references, spatial scale, and other information. These specific attributes include the following:

- Project type - type of hydropower projects of potential relevance (EHA \& NPD - existing hydropower assets and non-powered dams; All - refers to any type of hydropower project)

- Area - Spatial scale of relevance to a given question

- Biota - an indication of whether question is directly related to biota ("Y"= Yes, "N"=No).

- Taxa - an indication of whether answer to the question could be taxa specific

- KeyQ - an indication of whether the question is a "key" structural question or not (where some answers might depend on others) ("Y"= Yes, "N"=No).

○ Reference - literature reference used to develop the question

- Bibliography: Bibliography of all references used to create questions

- Q_DB: Database of unique question-river function combinations used to automatically calculate summary tables based on responses in the questionnaire. [Note: Alteration of the database content or structure will influence the summary output and diagrams. Users should not modify unless they have good reason to do so and are familiar with Microsoft Excel Visual Basic programming].

- List: Used to create standard values for entry in Questionnaire. [Note: Alteration of the list will influence the questionnaire, summary output, and diagrams. Users should not modify unless they have good reason to do so and are familiar with Microsoft Excel Visual Basic programming].

When you open the Excel file, you will be prompted to enable the macro-enabled features. Click "yes" when prompted whether you want to "update" links to external sources. Navigate to the "Instructions" spreadsheet and review the instructions (Figure 2.1). Get familiar with all spreadsheets mentioned above. 


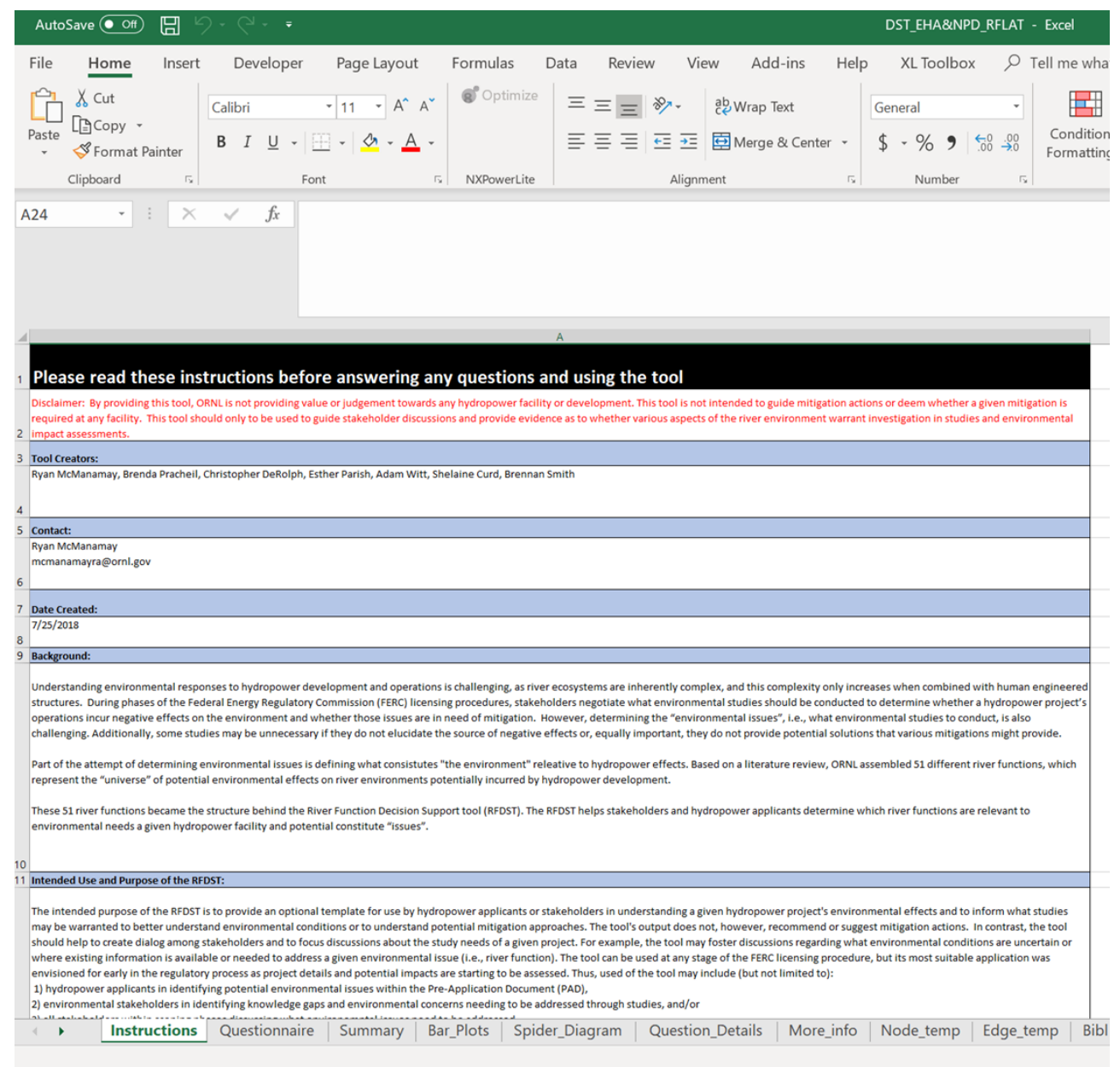

Figure 2.1. Instruction spreadsheet providing an overview of background, purpose, and general insructions for use.

\subsubsection{Completing the Questionnaire}

- Navigate to the Questionnaire spreadsheet (Figure 2.2). Answer questions using drop-down boxes (first response option highlighted in yellow) - see Figure 2.3.

- If a question is unclear or confusing, use the navigation buttons beside each question (red circle, Figure 3A) to navigate to the "More Info" Spreadsheet (Figure 2.3B). Additional justification is provided for questions prone to interpretation or needing more information. An example is highlighted in yellow (Figure 3B). Navigation buttons are available to allow you to conveniently return back to the same place on the questionnaire (red circle, Figure 2.3B)

- Where relevant, be sure to select whether a question pertains to a specific taxa by selecting "Yes" for each respective column that applies, or "No" if a question does not apply to a given taxa, or if you're uncertain, then select "uncertain" (Figure 2.4).

- Once you have completed all answers to the Questionnaire, you can click on the "Go to Summary" button to navigate to the "Summary" spreadsheet (red circle, Figure 2.5). 


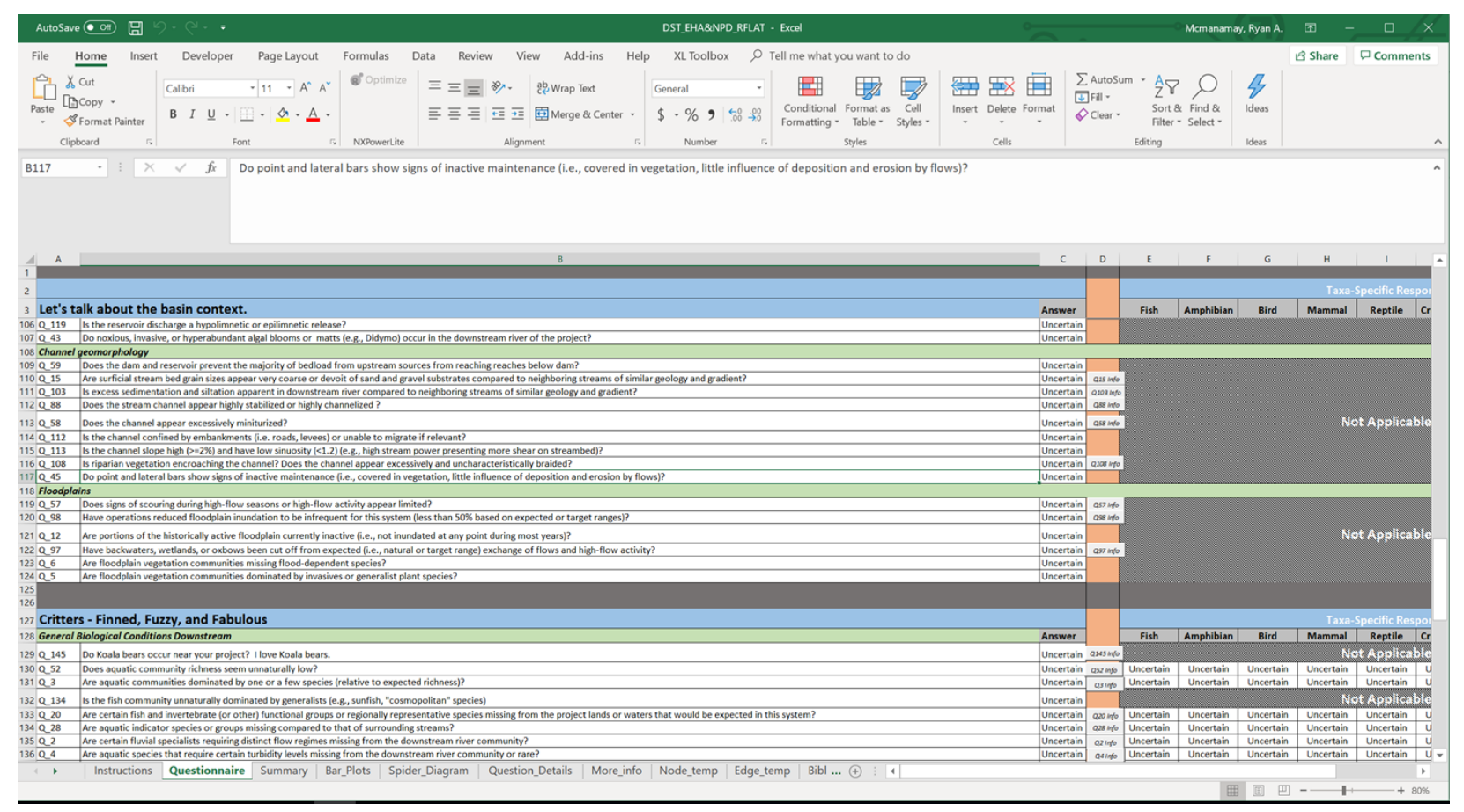

Figure 2.2. Questionnaire spreadsheet.

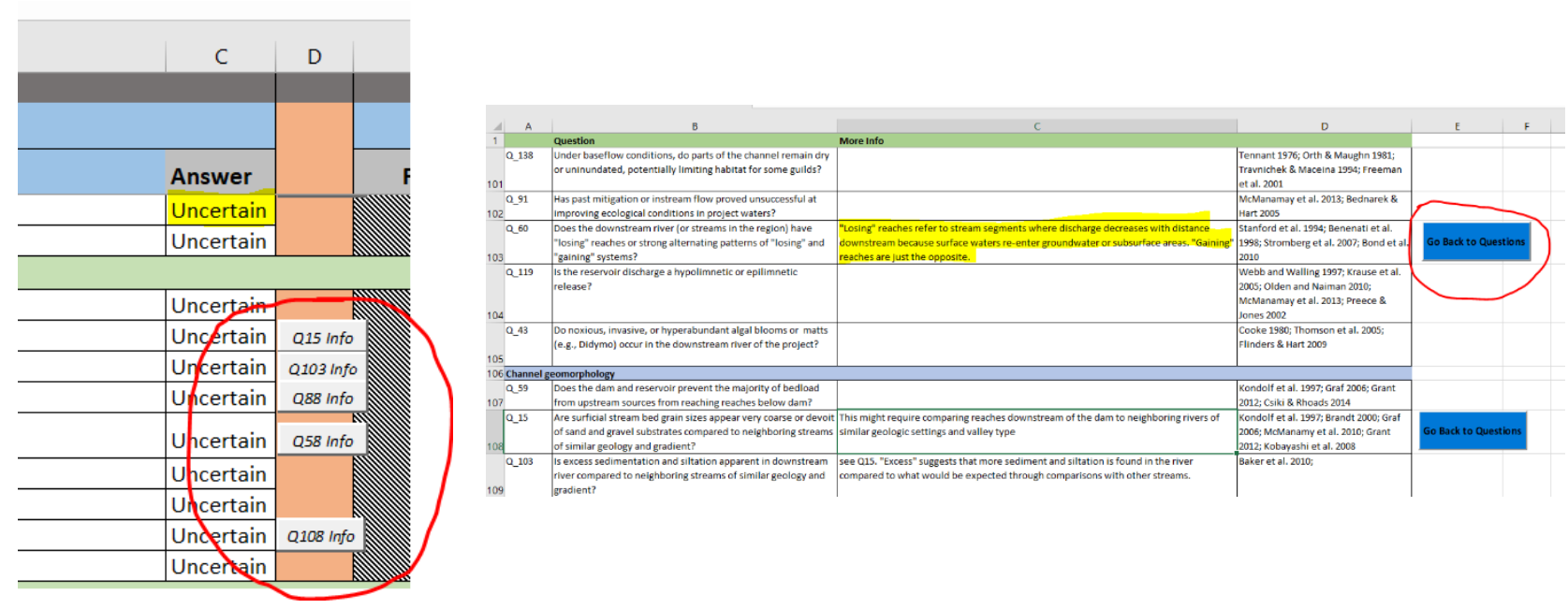

Figure 2.3. (A) Inset displays the response to questions provided by a drop-down list. The response option for the first question is highlighted in yellow. Red circle highlights the navigation buttons to the "More_info" spreadsheet. (B) the "More_info" spreadsheet provides more clarity or explanation behind the questions. 


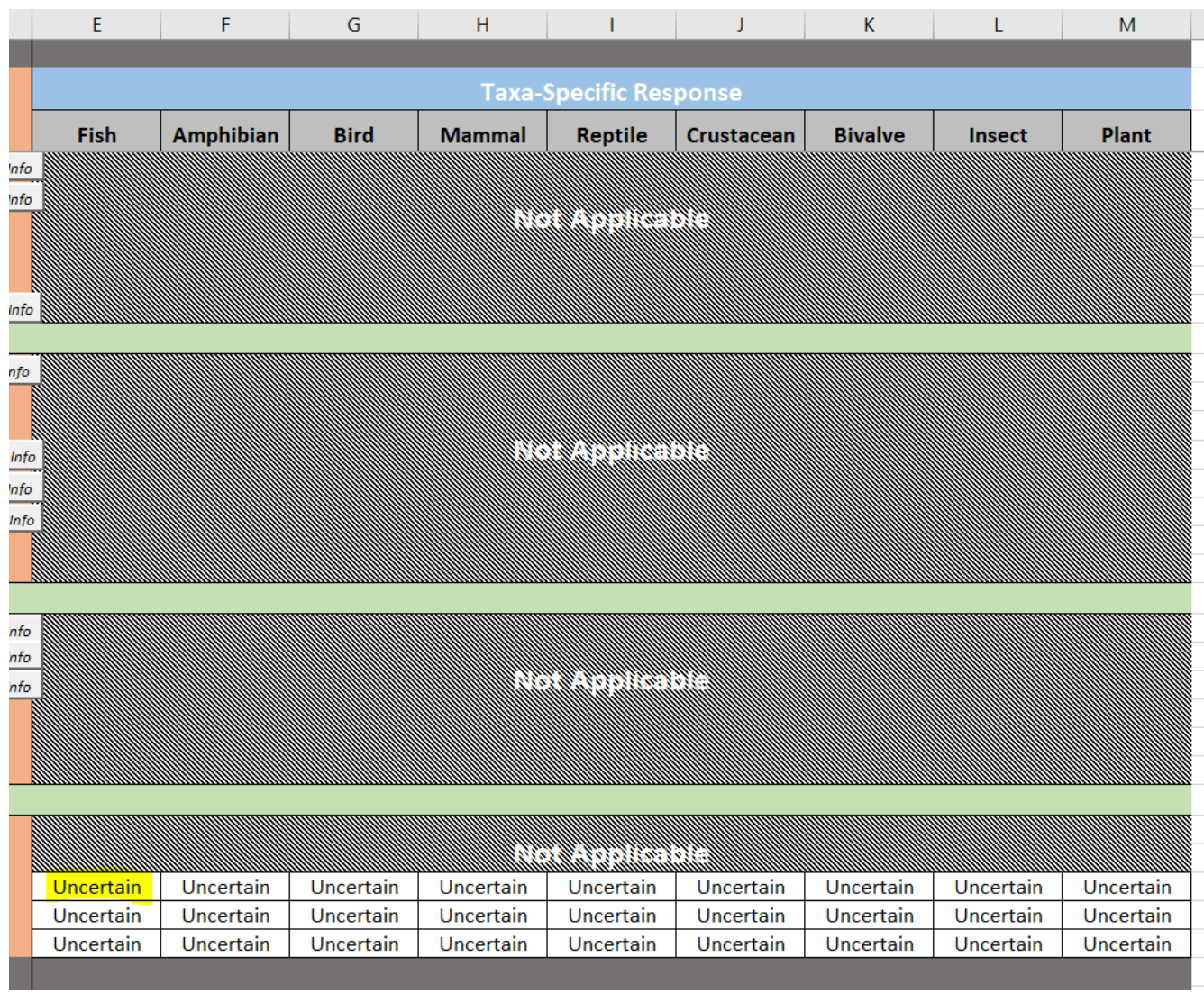

Figure 2.4. Section of questionnaire for determining whether specific taxa (columns) apply to each question. The first response is highlighted in yellow.

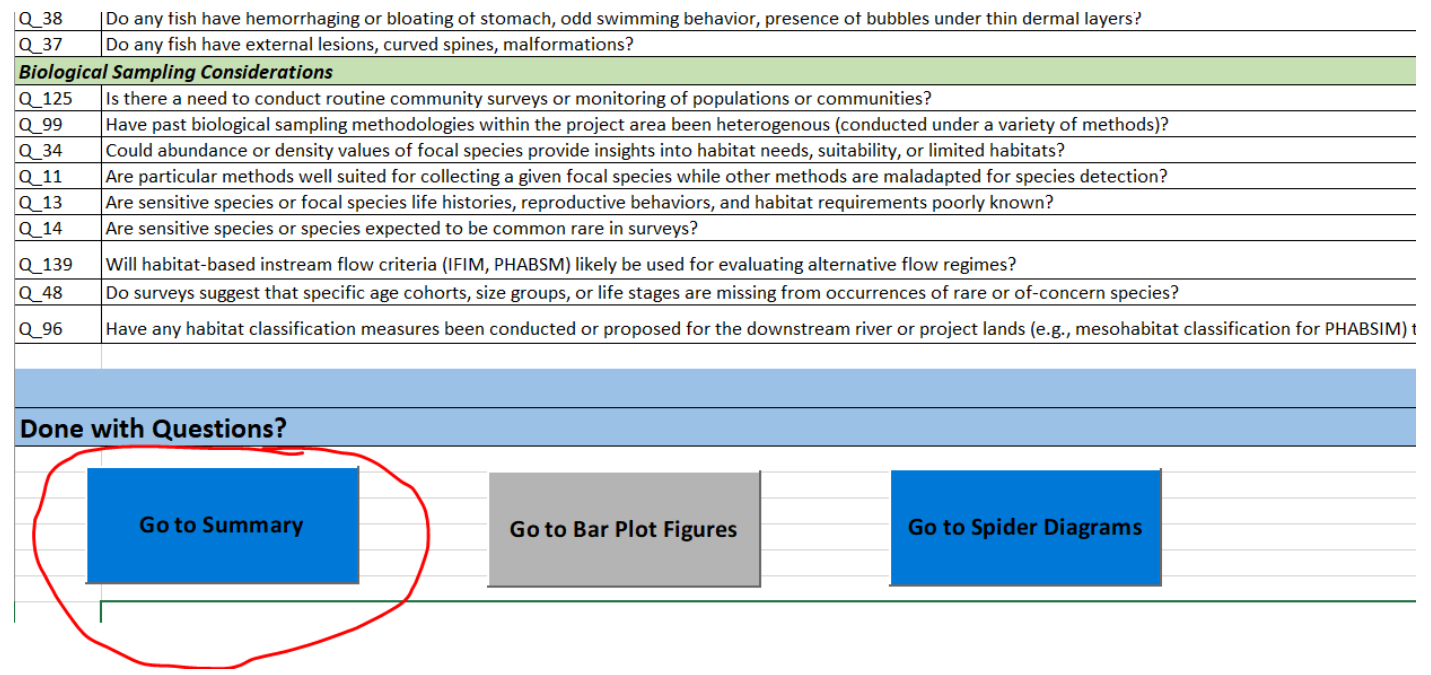

Figure 2.5. At the bottom of the questionnaire, there is a navigation button (red circle) that takes user to the tabular summary. 


\subsubsection{Interpreting the Questionnaire Output}

- The Summary spreadsheet provides a tabular summary of the number of questions answered "yes", "no", or "uncertain" (blue circle) related to a given river function (highlighted in yellow, Figure 2.6). Recall that a given question can pertain to more than one river function.

- The number of questions answered "yes" and relevant to specific taxa (black circle) or particular spatial scales (green circle) are also summarized (Figure 2.6).

- Click on the "Go to Bar Plot Figures" (red circle, Figure 2.6) to navigate to that page.

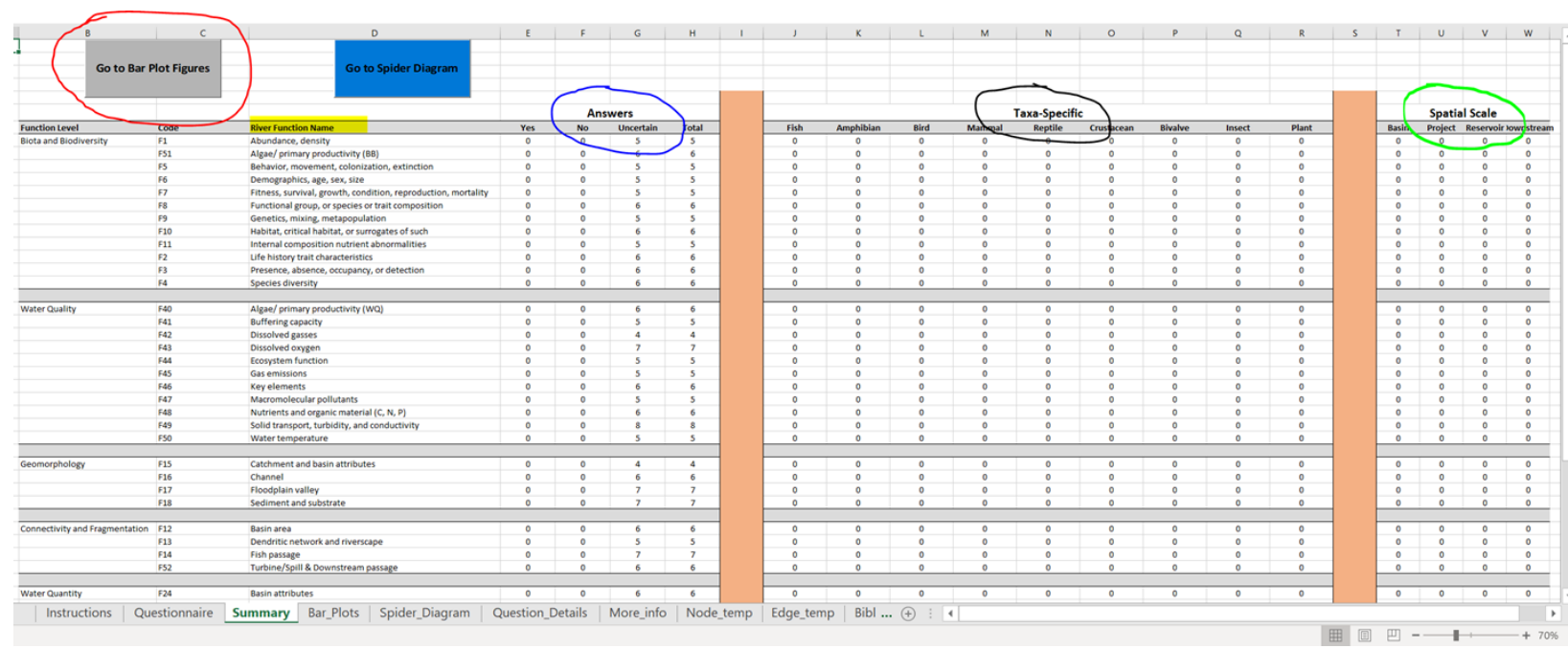

Figure 2.6. Summary spreasheet. River functions are listed in rows (up to down), whereas counts of responses are in columns. Total enumeration of "yes", "no", and "uncertaint" answers relevant to each river function are provided in the answers section (Blue circle). The total number of questions answered "yes" and applicable to each taxa-type are provided in the middle section (black circle), whereas the number of questions answered "yes" and applicable to specific spatial scales are provided in the far right section (green circle). Navigation buttons to the bar plot figures

(red circle) and spider diagram is provided.

- Once on the Bar_Plot spreadsheet (Figure 2.7), you will see three bar plots, two of which have summary pie charts underneath. You will notice that there are navigation buttons provided but also an ability to print the bar charts to .pdf files to save the output.
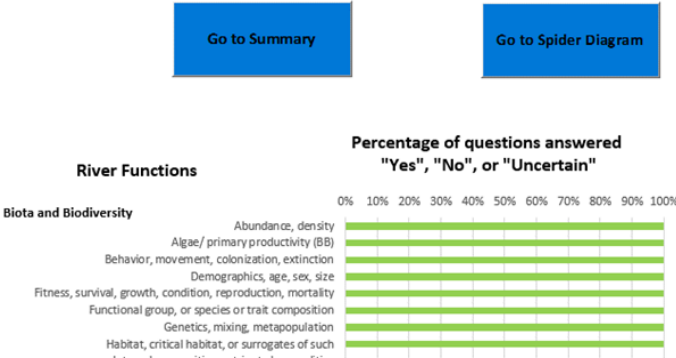
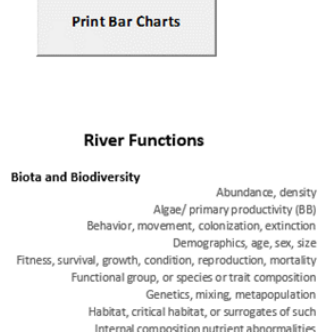

Explanation:

The plots represent the evidence that studies or assessmen Higher percentages of questions answered "yes" for any rivi "yes" for any river function can be related to specific spatial

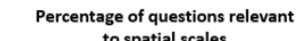
to spatial scales $10 \% 20 \% 30 \% 40 \% 50 \% 60 \% 70 \% 60 \% 690 \% 100 \%$

Figure 2.7. Top of Bar_plot spreadsheet with navigation buttons and first two bar plots.

- The bar plot on the far left represents the percentage of "yes", "no", and "uncertain" questions for a given river function (Figures 2.7-8). In short, they summarize the evidence that studies or assessments of specific environmental issues (i.e. river functions) may be warranted based on percentage of "yes" 
responses and issues that may be uncertain. River functions are listed vertically and represent different facets of the environment (Figure 2.8).

- Higher percentages of questions answered "yes" for any river function indicates more evidence that a river function is affected by development or operations at the facility. This may suggest that studies or assessments for that river function may be needed.

- Additionally, the percentage of questions answered "yes" for any river function can be related to specific spatial scales (Figure 2.9) or specific taxa that are most relevant in order to study or assess that function (Figure 2.10). This provides users with an indication of what spatial scales are most applicable to studies and the taxonomic groups that may require the most attention.

- Find the navigation buttons at the top of the bar_plot spreadsheet and click on "Go to Spider Diagram" (Figure 2.7)

- The Spider diagram (Figure 2.11) relies on the same information presented in Figure 2.8 but displays it differently. The spider diagram represents evidence of which river functions may be affected by development or operations at the facility (Figure 2.11). Specifically, the proportion of questions answered "yes" for each river function provide an indication that the project has or will effect specific environmental factors. For instance, if River Function F1 - Abundance/density has a value of 0.75, then this indicates that $75 \%$ of questions related to abundance and density were answered "yes". This suggests that studies monitoring abundance may be needed. Refer to the "relevant taxa" in the "Bar Plot Figures" to determine which taxa may need to be monitored.

- The Spider_Diagram spreadsheet provides navigational buttons and print commands (Figure 2.12). Users can print either the spider diagram or the river function summary table. 


\section{River Functions}

Biota and Biodiversity

Abundance, density
Algae/ primary productivity (BB)
Fitness, survival, growth, condition, reproduction, mortality
Functional group, or species or trait composition
Genetics, mixing, metapopulation
Habitat, critical habitat, or surrogates of such
Internal composition nutrient abnormalities
Life history trait char acteristics
Presence, absence, occupancy, or detection
Species diversity
Tater Quality
Algae/ primary productivity (WQ)
Buffering capacity
Dissolved gasses
Dissolved oxygen
Ecosystem function
Gas emissions
Key lements

te

Reservoir inundation

\section{Percentage of questions answered}

"Yes", "No", or "Uncertain"

$\begin{array}{llllllllllllllllllllll}0 \% & 10 \% & 20 \% & 30 \% & 40 \% & 50 \% & 60 \% & 70 \% & 80 \% & 90 \% & 100 \%\end{array}$

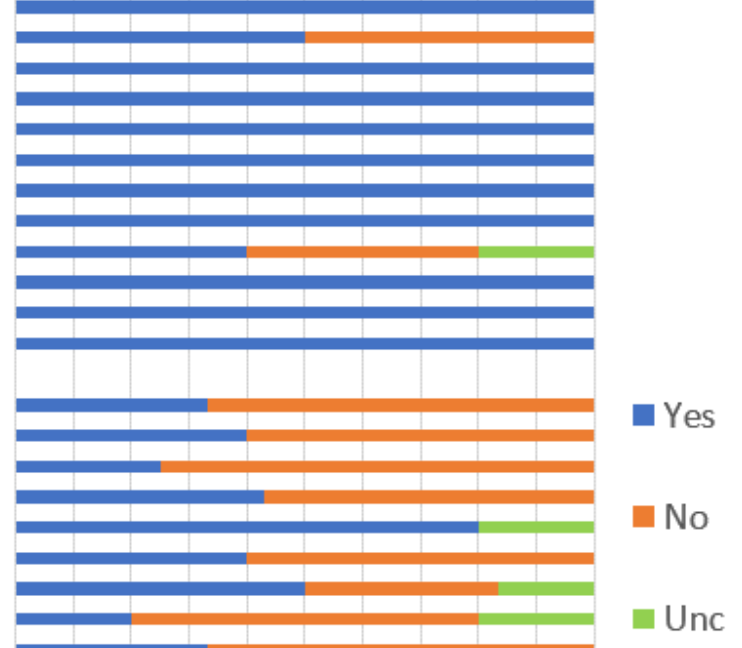

Yes

No

Unc
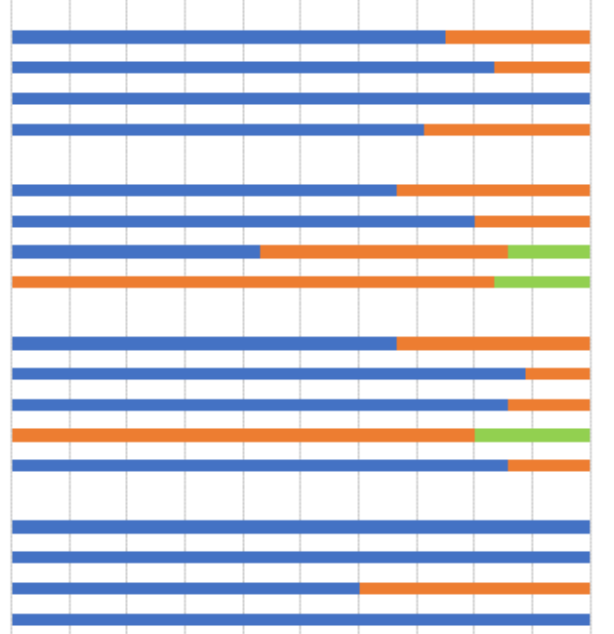

Figure 2.8. Bar plot depicting the percentage of "yes", "no", and "uncertain" responses relevant to each of the river functions. The example provided represents responses to the questionnaire with respect to Smoky Mountain Hydropower Project in North Carolina and Tennesee. 


\section{River Functions}

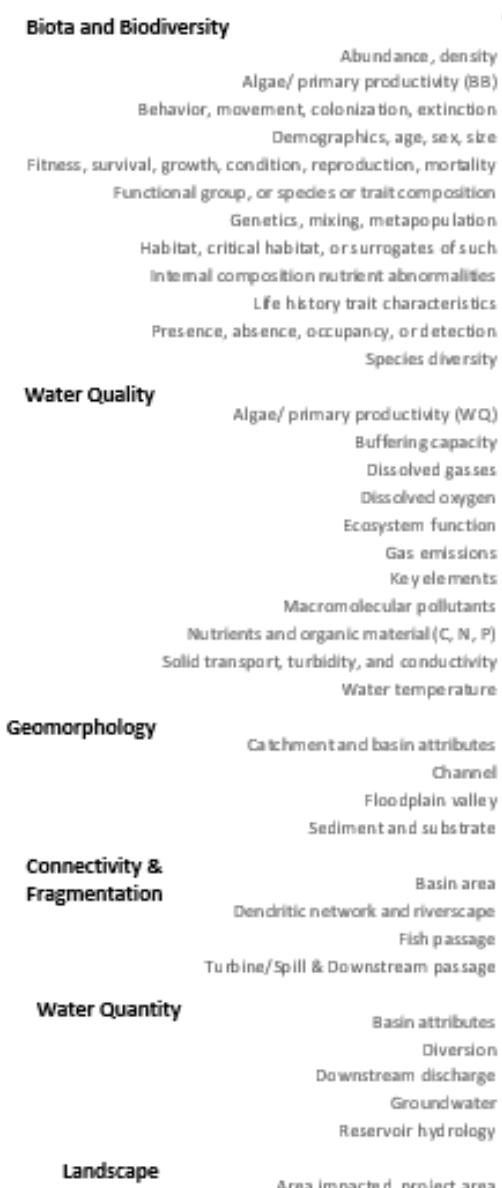

Landscape

Percentage of questions relevant

to spatial scales

$0 \% 10 \% 20 \% 30 \% \quad 40 \% 50 \% 60 \% 70 \%$ 80\% $90 \% 100 \%$

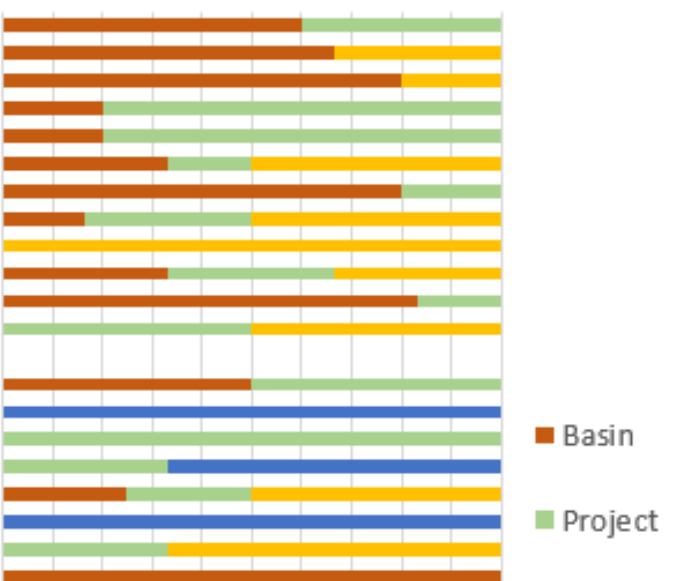

- Reservoir

Downstrm
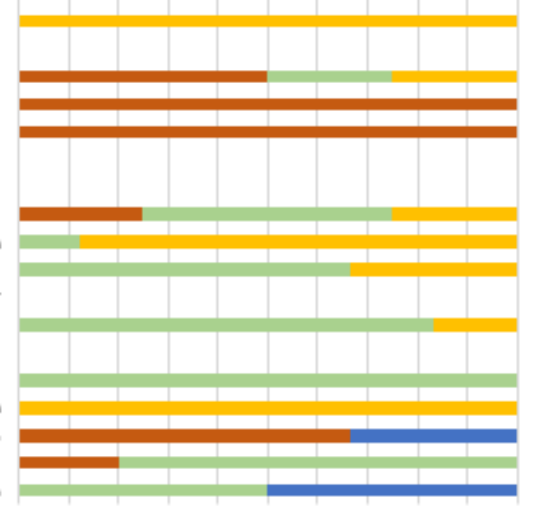

Spatial Summary

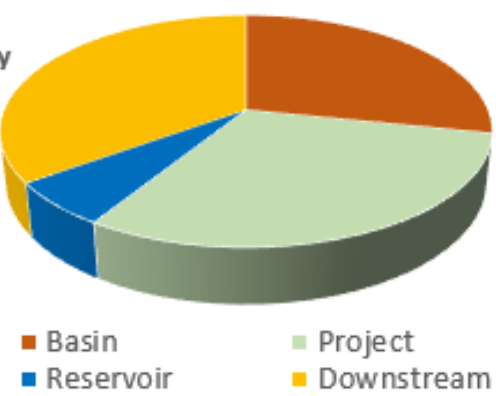

Figure 2.9. Bar plot depicting the percentage of "yes" responses that were relevant to specific spatial scales and a given river function. The pie chart provides a summary of all questions answered "yes" and relevant to a given spatial scales. The example provided represents responses to the questionnaire with respect to Smoky Mountain Hydropower Project in North Carolina and Tennesee. In this case, most "yes" responses were relevant to the entire project or basin or environments downstream. Fewer responses were relevant to the reservoirs associated with the project. 


\section{River Functions}

Biota and Biodiversity

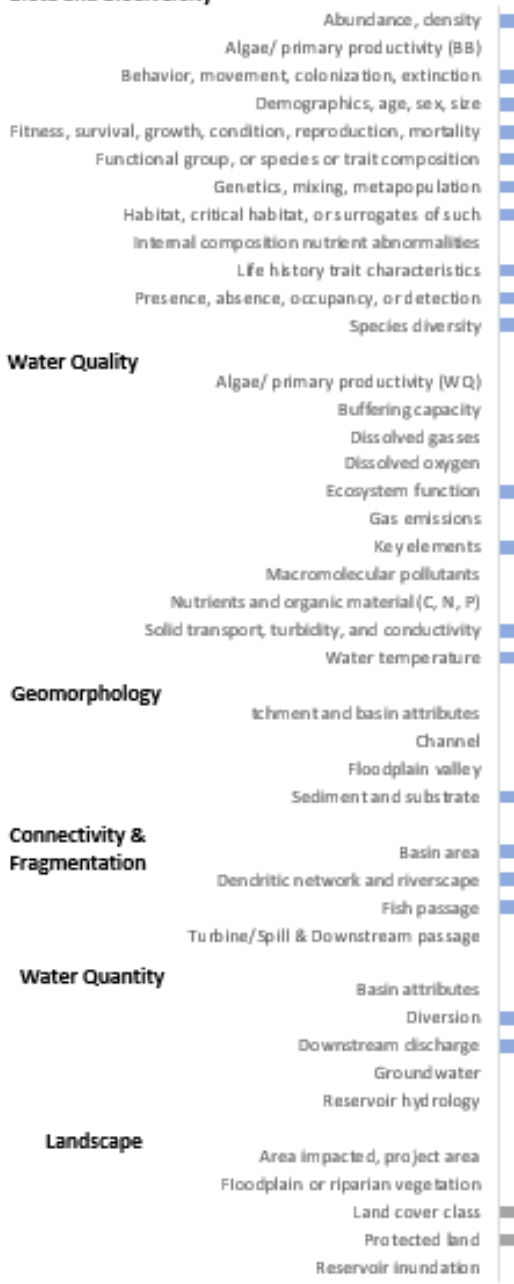

$0 \% 10 \% 20 \% 30 \% 40 \% 50 \% \quad 60 \% 70 \% 80 \% \quad 90 \% 100 \%$
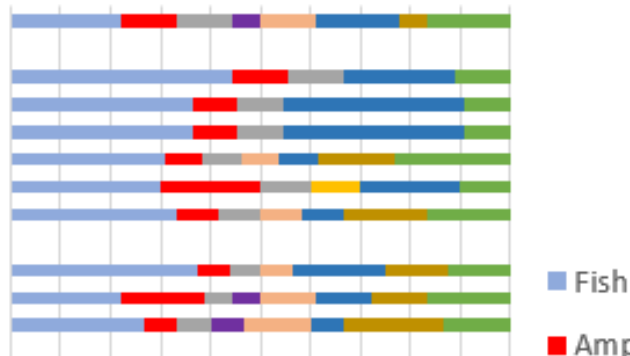

- Amphibian

Bird

Mammal

- Reptile

Crustacean

- Bivalve

- Insect

- Plant

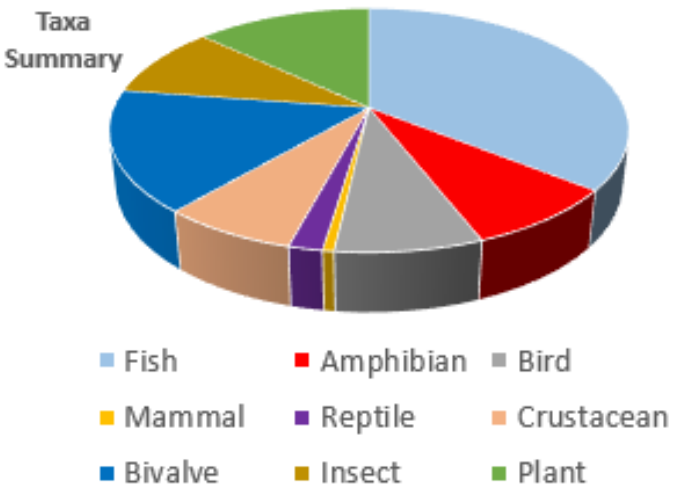

Figure 2.10. Bar plot depicting the percentage of "yes" responses that were relevant to specific taxa and a given river function. The pie chart provides a summary of all questions answered "yes" and relevant to a given taxonomic group. The example provided represents responses to the questionnaire with respect to Smoky Mountain Hydropower Project in North Carolina and Tennesee. In this case, most "yes" responses were relevant to fish and mussels; however, many taxa were relevant to the Smoky Mountain project as there are multiple developments and significant land assets. 


\section{Proportion of Questions Answered "Yes" for each River Function}

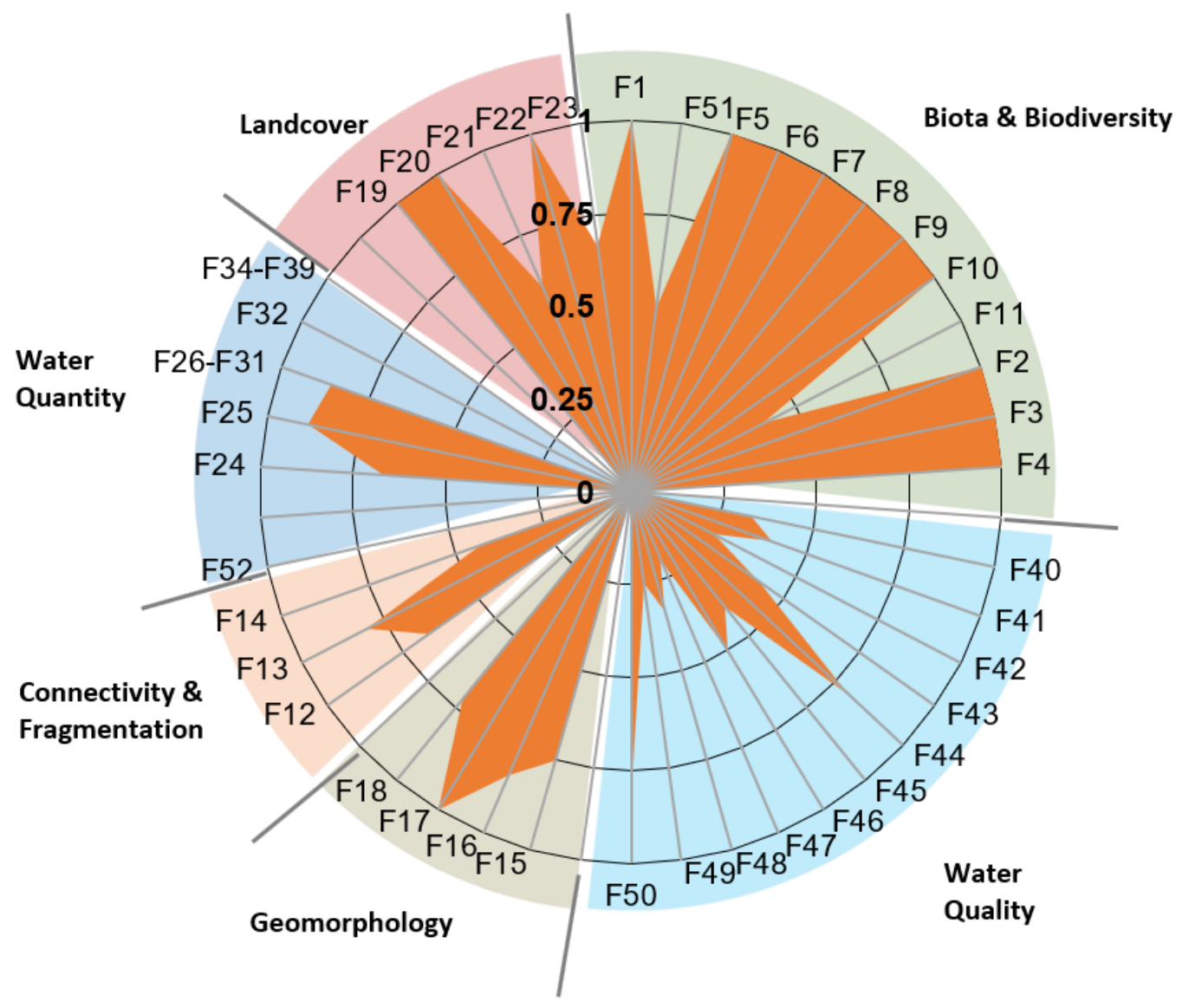

Figure 2.11. Spider diagram depicting the proportion of questions answered "Yes" for each river function. The diagram provides the same information captured in Figure 2.8. These proportions represent the likelihood that a river function is affected by the hydropower facility and ranges from 0 to 1 . This example is provided for Smoky Mountain Hydropower Project in North Carolina and Tennessee. The diagram suggests that certain river functions in all six categories are affected by operations, with many of the biota and biodiversity functions having a high likelihood of being affected. 


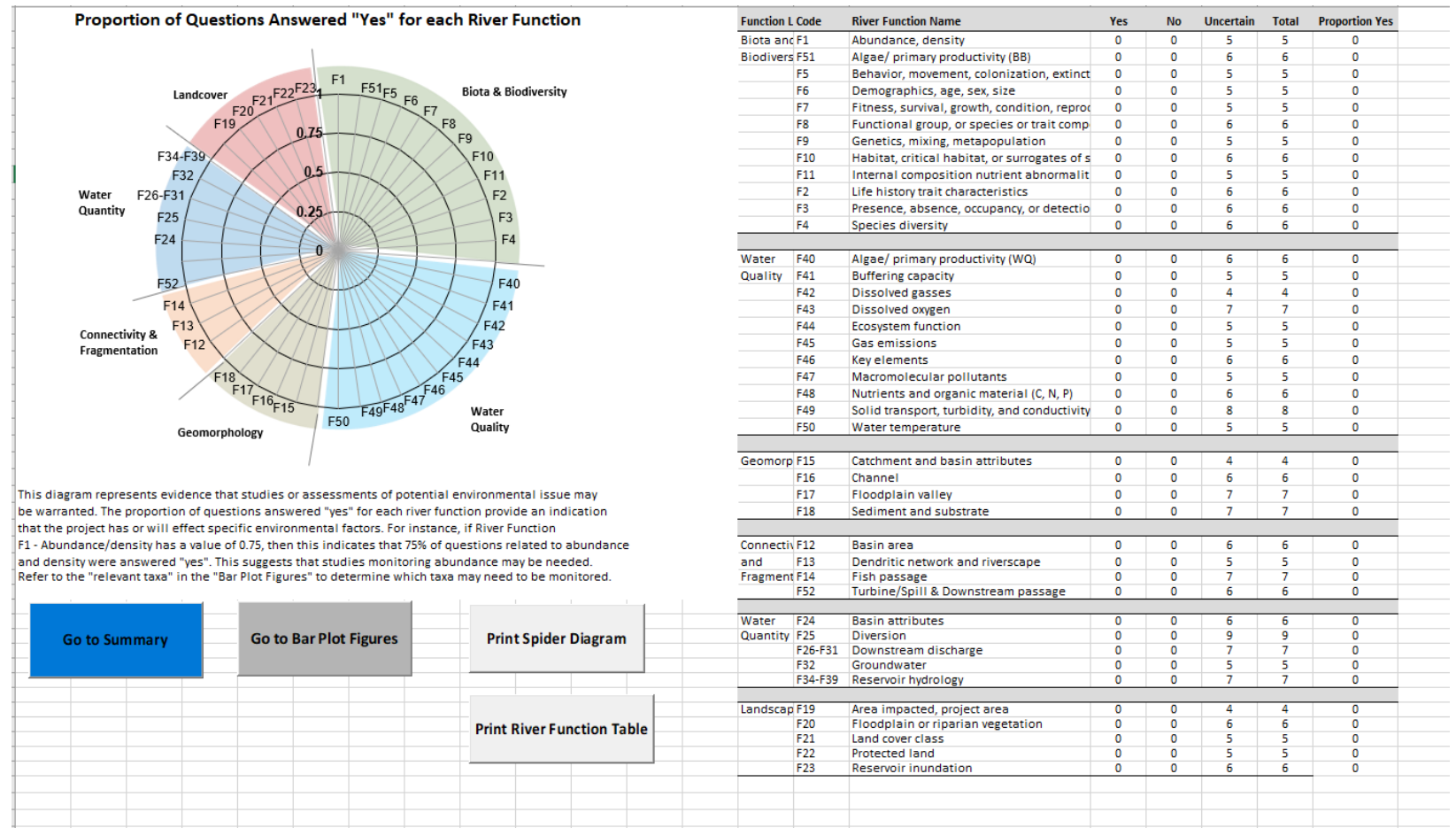

Figure 2.12. Spider diagram spreadsheet provides navigational buttons (to navigate to other sheets) and provides convenient print buttons to print the diagram or the river function summary table to .pdf. 


\section{QUESTIONNAIRE CROSS-CUT WITH REGULATORY CRITERIA}

\subsection{BACKGROUND}

The Questionnaire is a scientific tool based on scientific principles. It is flexible in that it can easily be applied to many different regulatory procedures, including FERC licensing. The Code of Federal Regulations (CFR) Title 18-Conservation of Power and Water Resources Chapter 1 outlines the role and conduct of FERC and the standards and procedures of the federal hydropower licensing process. Subchapter 5 (CFR 18, $\S$ ) outlines the Integrated Licensing Process, which includes criteria for stakeholders making study requests (CFR $18, \S 5.9$ ) and criteria for the applicant in developing a study plan (CFR 18, § 5.11) (see FERC 2005). Appropriate use of the Questionnaire, and the results obtained from its use, can generally be helpful in addressing the following sections of $\S 5.9$ (b) for study request criteria, which are equally analogous to sections of $\S 5.11(\mathrm{~d})$ :

- $\$ 5.9$ (b.1). Describe the goals and objectives of each study proposal and the information to be obtained

- $\$ 5.9$ (b.4). Describe the existing information concerning the subject of the study proposal, and the need for additional information

- $\quad \S 5.9$ (b.5). Explain any nexus between project operations and effects (direct, indirect, and/or cumulative) on the resource to be studied, and how they study results would inform the development of license requirements.

\subsection{1 $§ 5.9(b .1)$ and $§ 5.11(d .1)$}

In making a study request or in developing a study plan, stakeholders and applicants, must establish the goals and objectives of a given study and what information is required to meet those objectives. The Questionnaire assists all parties in establishing and understanding the rationale and justification behind why some aspects of the river environment (i.e., functions) are likely to have been affected by operations, and why others have not been. It also requires all parties to critically assess environmental conditions, compile and analyze existing information on environmental conditions and effects, and gain consensus over facts and data, in hopes of identifying natural resource issues that are well-justified by scientific information. Alternatively, the Questionnaire also highlights areas that are highly uncertain and may require additional information to fully understand. Finally, the nature of questions in the Questionnaire helps develop the scope and understand the role of specific studies in identifying causal relationships between operations and environmental conditions. In this way, the Questionnaire identifies the most relevant spatial scales and taxa for study or mitigation design.

The Questionnaire is a tool that supports, but does not replace, complex negotiation dialogue and procedures. In most relicensings, there is a multitude of study requests that could be used to address the natural resource issues identified. The Questionnaire provides all parties with a transparent evaluation of the environmental conditions present at the facility that have the highest likelihood of being impacted by construction or operation activities at a variety of temporal and spatial scales based on existing information. While the Questionnaire tallies the types of responses for questions about each function, it does not set thresholds for the number of "yes" responses indicate a river function should or should not be studied. Similarly, the questionnaire does not how or whether impacts to a river function could be mitigated. 


\subsection{2 $§ 5.9(b .4)$ and $\S 5.11(d .3)$}

Studies are typically used to fill information gaps, i.e. gaps in knowledge about project operation effects on environmental resources and potential outcomes of alternative mitigation strategies. Obviously, justifying any study or planning for a study requires parties to be cognizant of existing information, from the Pre-Application Document (PAD) or other sources. This prevents studies from being redundant with past efforts (e.g. previous relicensing) or, in the least, helps ensure studies are appropriately focused on filling information gaps. The use of the Questionnaire facilitates the process of identifying existing information. The instructions of the Questionnaire explicitly stipulate that to answer any question "yes" or "no" requires that a user must provide some existing information (e.g., past study, data, picture, stream gage reading, etc.) to qualify the response. The Questionnaire indirectly benefits the study request and study plan process through assisting in the development of the PAD. If an applicant uses the Questionnaire to develop the PAD, the early process of gathering and documenting sources of information could provide more efficient communication among parties and result in time savings in sequent licensing steps.

The negotiation process must determine whether the existing information is sufficient to understand project effects on the environment or whether more information is needed. The Questionnaire helps to identify environmental resources whose condition is highly uncertain and requires gathering of more information or the justification for a study request. The Questionnaire also helps identify the type and spatiotemporal scales of data required to understand environmental conditions.

\subsection{3 $§ 5.9(b .5)$ and $\S 5.11(d .4)$}

The Questionnaire can assist parties determine what effected resources can be mitigated through understanding causal linkages between the project and resources, including the role of diffuse stressors at larger spatial- and temporal-scales. Clear connections between the project operations and the effects on environmental resources must be established. The Questionnaire helps all parties draw lines of inference between project operations and direct or indirect effects on river functions. Questions were developed from a review of scientific literature and focus on well-established and common relationships between hydropower and river environments. The Questionnaire also poses questions that require users to critically evaluate whether environmental conditions are related to project operations or an artifact of human activities upstream or in adjacent basins outside the applicant's control or outside the purview of the project. For instance, several questions ask whether hydrology or water quality conditions at the project are influenced from upstream sources. In these cases, the role of project operations on the current environmental conditions must be isolated from other anthropogenic stressors. Related to this, questions require critically analyzing conditions and causal factors, some of which cannot be mitigated with a costeffective solution.

The Questionnaire provides an objective basis from which study request and plans can be made. A highly controversial aspect of understanding project nexus with environmental resources is that of delineating the baseline condition - i.e. the reference or standard from which one measures the current state of resources. The identification of the quantity and identity of resources are affected by project operations is contingent on baseline delineation. FERC's policy defines baseline conditions as the environmental condition at the time of licensing, specifically stipulating that applicants are generally not required to recreate pre-project conditions (i.e., historical conditions) (FERC 2012). However, in order to evaluate the effects of project operations and alternatives, FERC requires that continuing effects on resources be assessed (presumably including those established since the time of development), as long as the purpose of the information is to evaluate appropriate mitigation under continued project operation (FERC 2012). The Questionnaire provides a transparent evaluation of environmental conditions and a tally of which aspects of the river environment have been affected by project operations. Some of the questions do 
require users to identify a baseline to make comparisons and understand environmental effects appropriately. These comparisons may include evaluating conditions at neighboring regulated or nonregulated river systems to objectively establish causal relationships between project operations and resources, but also understand what factors can be reasonably mitigated. The Questionnaire is flexible in that questions can be answered differently depending on how the baseline condition is defined. Given that the questionnaire is grounded in scientific literature that predominately measures resource effects through comparisons of pre- and post- development and regulated and non-regulated systems, one suggestion is that the Questionnaire be used to develop a holistic understanding of the current state of the river ecosystem (and associated terrestrial ecosystems) relative to stated resource goals using river functions as indicators. Establishing this understanding does not suggest that mitigation is warranted or even achievable under continued project operations. However, a comprehensive understanding of the ecosystem characteristics inclusive of present and historical stressors can be useful in isolating the most meaningful causal factors between project operations and environmental conditions including which factors can be mitigated to improve conditions.

\section{ACKNOWLEDGEMENTS}

This research was sponsored by the U.S. Department of Energy, Water Power Technologies Office within the Office of Energy Efficiency and Renewable Energy under contract DEAC05-00OR22725. We wish to thank the Mission and Science Advisory Boards for their roles in evaluating the questionnaire and providing valuable feedback. We thank Tim Welch, Dana McCoskey, and Corey Vezina for their guidance on the project.

\section{REFERENCES}

FERC (Federal Energy Regulatory Commission). 2005. Understanding the Study Criteria. Integrated Licensing Process. Office of Energy Projects. April 6, 2005. Available at: https://www.ferc.gov/industries/hydropower/gen-info/licensing/ilp/eff-eva/study-criteria.pdf

FERC (Federal Energy Regulatory Commission). 2012. A guide to understanding and applying the Integrated Licensing Process Study Criteria. Office of Energy Projects. March 2012. Available at: https://www.ferc.gov/industries/hydropower/gen-info/guidelines/guide-study-criteria.pdf

McManamay, R.A., S.K. Brewer, H. Jager, M. Troia. 2016a. Organizing environmental flow frameworks to meet US Hydropower mitigation needs. Environmental Management 58: 365-385

McManamay, R.A., C. Oigbokie, S-C. Kao, M.S. Bevelhimer. 2016b. A classification of US hydropower dams by their modes of operation. River Research and Applications DOI: 10.1002/rra.3004

McManamay, R.A., B.K. Peoples, D.J. Orth, C.A. Dolloff, and D.C. Matthews. 2015a. Isolating causal pathways between flow and fish in the regulated river hierarchy. Canadian Journal of Fisheries and Aquatic Sciences 72: 1731-1748.

McManamay, R.A., N. Samu, S-C. Kao, M.S. Bevelhimer, and S.C. Hetrick. 2015b. A multi-scale spatial approach to address environmental effects of small hydropower development. Environmental Management 55: 217-243.

McManamay, R.A. 2014. Quantifying and Generalizing Hydrologic Responses to Dam Regulation using a Statistical Modeling Approach. Journal of Hydrology 519: 1278-1296. 
McManamay, R.A., D.J. Orth, C.A. Dolloff, D.M. Mathews. 2013b. Application of the ELOHA framework to regulated rivers in the Upper Tennessee River basin. Environmental Management 51:1210-1235.

McManamay, R.A., D.J. Orth, J. Kauffman, M.D. Davis. 2013c. A database and meta-analysis of ecological responses to flow in the South Atlantic Region. Southeastern Naturalist 12 (Monograph 5): $1-36$.

McManamay, R.A., D.J. Orth, C.A. Dolloff. 2012. Revisiting the homogenization of dammed rivers in the Southeastern US. Journal of Hydrology 424-425: 217-237.

McManamay, R. A., D. J. Orth, C. A. Dolloff, and M. A. Cantrell. 2010. Gravel addition as a habitat restoration technique for tailwaters. North American Journal of Fisheries Management 30:1238-1257.

Norris, R.H., J.A. Webb, S.J. Nichols, M.J. Stewardson, and E.T. Harrison. 2012. Analyzing cause and effect in environmental assessments: Using weighted evidence from the literature. Freshwater Science 31:5-21.

Olden, J.D., and Naiman, R.J. 2010. Incorporating thermal regimes into environmental flows assessments: modifying dam operations to restore freshwater ecosystem integrity. Freshw. Biol. 55: 86-107. doi:10.1111/j.1365-2427.2009.02179.x.

Parish, E., B.M. Pracheil, R.A. McManamay, S.L. Curd, C.R. DeRolph, B.T. Smith. 2019. Review of environmental metrics used across multiple sectors and geographies to evaluate the effects of hydropower development. Applied Energy 238:101-118 https://doi.org/10.1016/j.apenergy.2019.01.038

Petts G. 1984. Impounded Rivers: Perspective for Ecological Management. John Wiley \& Sons: Chichester.

Poff NL, Hart DD. 2002. How dams vary and why it matters for the emerging science of dam removal. BioScience 52: 659-738.

Poff, N.L., and J.K.H. Zimmerman. 2010. Ecological responses to altered flow regimes: A literature review to inform the science and management of environmental flows. Freshwater Biology 55:194205.

Pracheil, B.M., R.A. McManamay, E.S. Parish, S.L. Curd, B.T. Smith, C.R. DeRolph, A.M. Witt, S. Ames, M.B. Day, W. Graf, D. Infante, D.L. McCoskey, K. Rugani, C. Vezina, T. Welch, A. West. (in review). A checklist of river function indicators for hydropower ecological assessment. Science of the Total Environment. 